\title{
Studies of Thrombin-induced Proteoglycan Release in the Degradation of Human and Bovine Cartilage
}

\author{
Emilia Furmaniak-Kazmierczak, ${ }^{*}$ T. Derek V. Cooke, ${ }^{*}$ Reg Manuel, ${ }^{\star}$ Allan Scudamore, ${ }^{*}$ Hugh Hoogendorn, ${ }^{\$}$ \\ Alan R. Giles, "\$\| and Michael Nesheim ${ }^{\neq \|}$ \\ Departments of ${ }^{\ddagger}$ Biochemistry, ${ }^{8}$ Pathology, "Medicine, and * Surgery, Queen’s University, Kingston, Ontario, K7L 3N6, Canada
}

\begin{abstract}
Because fibrin is commonly observed within arthritic joints, studies were undertaken to determine whether purified coagulation and fibrinolytic proteases degrade cartilage in vitro and to seek evidence for the activation of coagulation in arthritic joints through measurements of the levels of inhibitor-enzyme complexes and several other proteins associated with coagulation and fibrinolysis. The concentrations of 13 plasma proteins and complexes of thrombin and Factor Xa with antithrombin III were measured in synovial fluids recovered at the time of knee replacement surgery. All zymogens necessary to constitute the coagulation cascade were present. Thrombin and the combination of prothrombin plus prothrombinase induced proteoglycan release from both normal and arthritic cartilages. Factor $\mathrm{Xa}$ and plasmin induced release from diseased cartilage only, and urokinase, tissue plasminogen activator, and activated protein $\mathbf{C}$ were without effect at the levels used. At saturating levels of thrombin $(\geq 2.0 \mu \mathrm{M}) \mathbf{8 0 \%}$ of the proteoglycan content of normal cartilage was released within $24 \mathrm{~h}$. Thrombin, which is cationic, reversibly binds cartilage with $K_{\mathrm{d}}=7.0 \pm 1.0 \mu \mathrm{M}$ and $B_{\max }=820 \pm 70 \mathrm{ng} / \mathrm{mg}$ of human cartilage. Levels of thrombin-antithrombin III complexes in synovial fluids and arthritis were 4-fold higher in osteo(OA) and 43-fold higher in rheumatoid(RA) than in controls $(0.98 \mathrm{nM})$. Factor Xaantithrombin III complex levels were threefold lower in OA and fivefold higher in RA than in controls $(0.24 \mathrm{nM})$. These elevated levels of enzyme-inhibitor complexes imply a history of activation of coagulation within the joint, especially in RA. Since thrombin degrades cartilage in vitro and had been generated in vivo, as inferred by the existence of thrombin-antithrombin III complexes, intraarticular activation of coagulation may both contribute to the pathology of arthritis and comprise a target for therapy and diagnosis. (J. Clin. Invest. 1994. 94:472-480.) Key words: coagulation - rheumatoid arthritis - osteoarthritis
\end{abstract}

\section{Introduction}

Both rheumatoid and osteoarthritis (RA and OA $)^{1}$ are characterized by disruption of articular cartilage, considerable pain, and

Address correspondence to Michael E. Nesheim, Ph.D., Department of Biochemistry, Queen's University, Kingston, Ontario K7L 3N6, Canada. Received for publication 9 July 1992 and in revised form 22 February 1994.

J. Clin. Invest.

(c) The American Society for Clinical Investigation, Inc.

0021-9738/94/08/472/09 \$2.00

Volume 94, August 1994, 472-480 impairment of the use of affected joints $(1,2)$. Although a great deal of effort has been expended to determine the mechanisms responsible for cartilage destruction, and considerable progress has been made, the mechanism or mechanisms which ultimately underlie the phenomenon are not known (1-3). Most work to date, however, suggests that the destruction of cartilage in arthritis can be attributed substantially to inappropriate expression of proteolytic activity within the joint space and extracellular matrix. This may be coupled with either suppressed (RA) or enhanced (OA) synthesis of matrix components (1).

The integrity of cartilage and thus its ability to perform its mechanical function is maintained by a dynamic balance between synthesis and degradation of components of the extracellular matrix by factors elaborated by the chondrocytes. Among these factors are the latent neutral metalloproteinases procollagenase, progelatinase, and prostromelysin which, when activated, can catalyze the degradation of collagen and proteoglycans $(4,5)$. The enzymes derived from these zymogens may be neutralized by inhibitors released from chondrocytes $(6,7)$.

In an inflammatory milieu, the immune system also may participate in cartilage destruction, especially in RA in which monocytes, macrophages and neutrophils infiltrate the tissues of the joint and the joint fluid (8). These cellular elements can both elaborate mediators which influence the metabolic function of chondrocytes (e.g., interleukin 1, tumor necrosis factor, prostaglandins) and provide enzymes capable of activating latent metalloproteinases $(8-10)$. Elastase, liberated by the polymorphonuclear neutrophil, has been detected in the synovial fluids of rheumatoid and osteoarthritic joints at respective activity levels 10 - and 100-fold greater than that of plasma (11).

The potential also exists for the involvement of proteases of the fibrinolytic or coagulation systems in cartilage destruction. The ultimate enzyme of fibrinolysis, plasmin, not only catalyzes the activation of procollagenase and prostromelysin (12) but also directly catalyzes degradation of proteoglycans in vitro $(13,14)$. In addition, plasmin-derived fibrin degradation products have been detected in the synovium and synovial fluid of patients with rheumatoid arthritis $(15,16)$. Although activated clotting factors have not been reported in the diseased joint, Weinberg et al. (17) recently demonstrated by histological techniques the presence of fibrinogen, tissue factor, Factor XIII, cross-linked fibrin (D-dimer), urokinase-like plasminogen activator and alpha $a_{2}$-antiplasmin. In addition, the nearly universal existence of fibrin in the cartilage and synovial tissue in RA joints $(8,18)$, and its frequent presence in OA (19), indirectly indicates that thrombin activity is expressed in these diseases.

1. Abbreviations used in this paper: APC, activated protein C; GAGS, glycosaminoglycans; OA, osteoarthritis; PCI, protein C inhibitor; tPA, tissue plasminogen activator. 
Since thrombin is formed only by activation of its plasma precursor prothrombin (20), the presence of fibrin also suggests intraarticular activation of the coagulation cascade. That activation of coagulation in the diseased joint could occur is plausible, since plasma components are known to enter inflamed joints (8). In addition, activated monocytes are present to both supply tissue factor to initiate the extrinsic pathway and, along with platelets and neutrophils, provide the surface components required for the assembly of the Factor $\mathrm{X}$ and prothrombin-activating complexes (21-23). Thus, considerable published work indicates the potential within the diseased joint for expression of activities associated with both coagulation and fibrinolysis and a milieu conducive to their continued activation.

The purposes of this study were to determine whether specific purified coagulation and fibrinolytic proteases promote cartilage degradation in vitro and to examine synovial fluids for evidence of intraarticular coagulation in arthritis. The results indicate that the purified enzyme thrombin can interact with cartilage and induce its degradation in vitro. The zymogens of the coagulation cascade were found in substantial levels in the fluids of diseased joints, suggesting a potential for thrombin generation. In addition, covalent complexes of Factor $\mathrm{Xa}$ and thrombin with their physiologic inhibitor, antithrombin III, were found at elevated levels in synovial fluids of OA and RA joints, indicating that the coagulation cascade had been activated in those joints.

\section{Methods}

Materials. The human plasma proteins used in this study were all purified to apparent homogeneity as indicated by electrophoresis. Factor X, prothrombin, and protein $\mathrm{C}$ were isolated from eluates of barium citrate precipitates of human plasma by chromatography on DEAE-fast flow Sepharose and dextran sulphate agarose $(24,25)$. Bovine Factor $V$ was isolated as described previously (26). Plasminogen was isolated by affinity chromatography on lysine Sepharose, and plasmin was prepared with urokinase and re-chromatography on lysine Sepharose $(27,28)$. Factor Xa was prepared by incubating Factor X with the purified Factor $\mathrm{X}$ activator from Russell's Viper Venom, and subsequent affinity chromatography on benzamidine Sepharose (29). Thrombin was prepared by activating prothrombin with prothrombinase (Factor Xa, Factor Va, phospholipid vesicles, and $\mathrm{Ca}^{2+}$ ) and isolating the enzyme by chromatography on SPC-50 Sephadex (30). ${ }^{125}$ I-labeling of thrombin was accomplished by the Iodobead method (Pierce Chemical Co., Rockford, IL). Briefly, two iodobeads were rinsed in $1.0 \mathrm{ml}$ of $0.015 \mathrm{M}$ Tris- $\mathrm{HCl}$, $0.1 \mathrm{M} \mathrm{NaCl}$, pH 7.4. The buffer was discarded and $0.5 \mathrm{ml}$ of fresh buffer was added, followed by $1.0 \mathrm{mCi}$ of $\mathrm{Na}^{125}$ ( ICN Radiochemicals, Irvine, CA). The mixture was shaken intermittently for $5 \mathrm{~min}$ at $22^{\circ} \mathrm{C}$. The buffer plus $\mathrm{Na}^{125} \mathrm{I}$ were transferred into $0.5 \mathrm{ml}$ of thrombin solution $(740 \mu \mathrm{g} / \mathrm{ml})$ in the same buffer. The reaction was carried out at $22^{\circ} \mathrm{C}$ for $10 \mathrm{~min}$. The products were separated by gel filtration on a column of Sephadex G-25. The specific-radioactivity was $2.2-2.4 \times 10^{6} \mathrm{cpm} /$ $\mu \mathrm{g}$ of thrombin. The ${ }^{125}$ I-labeled thrombin prepared by this method comigrated with unlabeled thrombin on SDS-PAGE and was active in a thrombin clotting assay. Radiolabeled thrombin was mixed with unlabeled thrombin to yield a final specific radioactivity of 1.2-2.7 $\times 10^{5}$ $\mathrm{cpm} / \mu \mathrm{g}$. Factor Va was prepared by activation of Factor $\mathrm{V}$ by thrombin (26). Fibrinogen was isolated by the method of Straughn and Wagner (31). Antithrombin III was isolated by affinity chromatography on Heparin Sepharose (32). Activated protein $C$ was prepared by incubation of thrombin with subsequent removal of thrombin on SPC-50 Sepharose (25). Tissue plasminogen activator (Activase) was a generous gift from Dr. Gordon Veher of Genentech Inc., San Francisco, CA, and urokinase was purchased from Calbiochem, San Diego, CA. Procoagulant phos- pholipid (PCPS) vesicles were prepared from phosphatidylserine and phosphatidylcholine (1:3) by sonication and ultra centrifugation (33). The irreversible chloromethyl ketone thrombin inhibitor (PPA-CK) was obtained from Calbiochem. The sheep anti-human thrombin, goat antihuman Factor $\mathrm{X}$ and sheep anti-human antithrombin III affinity-purified polyclonal antibodies and all other antibodies were supplied by Affinity Biologicals (Hamilton, Ontario, Canada).

Cartilage. Specimens of normal adult bovine cartilage were excised under aseptic conditions from metacarpophalangeal joints obtained fresh from the abattoir (McFedridge Meats, Glenburnie, Ontario). Normal human cartilage specimens, when used, were obtained at autopsy from knees of individuals lacking clinical evidence of joint disease. Diseased specimens were obtained from resected tissue of patients undergoing total knee replacement. No special efforts were made to collect either more or less damaged cartilage in the diseased specimens. In all, samples from 11 patients with rheumatoid arthritis, 23 with osteoarthritis, and 5 controls (cadaver) were obtained. Full-depth plugs of $5 \mathrm{~mm}$ diameter were cut with a coring tool, preweighed, and then stabilized for $24 \mathrm{~h}$ in serum-free Dulbecco's medium (Flow Laboratories, McLean, VA) supplemented with $10 \mathrm{mM}$ Hepes, penicillin $(100 \mathrm{U} / \mathrm{ml})$ and streptomycin $(100 \mu \mathrm{g} / \mathrm{ml})$ at $37^{\circ} \mathrm{C}$. In some experiments the samples of cartilage were subjected to three freeze-thaw cycles in liquid nitrogen to selectively kill chondrocytes, or heated at $60^{\circ} \mathrm{C}$ for $30 \mathrm{~min}$ to inactivate all intra- and extracellular activities (34).

Synovial fluids. Samples of synovial fluids were collected from RA and $\mathrm{OA}$ patients at the time of knee replacement and from control (cadaver) joints. Fluids were collected into vacutainer tubes (Becton Dickinson Vacutainer Systems, Rutherford, NJ) containing EDTA $\left(\mathrm{K}_{3}\right)$ and centrifuged for $5 \mathrm{~min}$ at $6,600 \mathrm{~g}$ at $22^{\circ} \mathrm{C}$. Supernatants were collected and immediately frozen at $-70^{\circ} \mathrm{C}$ until used.

The effects of coagulation and fibrinolytic enzymes on the release of proteoglycans from cartilage. Cartilage explants were incubated for $24 \mathrm{~h}$ with the following alternative reagents: $(a)$ Factor Xa $(10 \mathrm{nM})$; (b) plasmin (100 nM); (c) activated protein C (50 nM); $(d)$ tissue plasminogen activator $(50 \mathrm{nM}) ;(e)$ urokinase (200 Plough units $/ \mathrm{ml})$; $(f)$ thrombin $(0-10 \mu \mathrm{M})$; or $(g)$ prothrombin $(0.1 \mu \mathrm{M})$ plus prothrombinase ( $10 \mathrm{nM}$ Factor $\mathrm{Xa}, 10 \mathrm{nM}$ Factor V, $10 \mu \mathrm{M}$ PCPS vesicles, and $5 \mathrm{mM} \mathrm{Ca}^{2+}$ ). The concentrations of the proteins were calculated from measurements of absorbance at $280 \mathrm{~nm}$ and published extinction coefficients and molecular weights. After the incubation, samples of the media were collected and analyzed for proteoglycan (glycosaminoglycan) content by the 1,9-dimethylmethylene blue dye (DMB) binding assay (35). The DMB assay was performed in a 96-well microtiter plate. The samples were diluted 1:16 with DMB solution (35) and absorbances at 535 $\mathrm{nm}$ were immediately measured on a Titertek Multiscan MCC/340 ELISA Reader. A standard curve was prepared using chondroitin sulfate from bovine trachea (BDH Chemicals Ltd., Poole, England). The assay was linear for sample concentrations ranging from 5 to $250 \mu \mathrm{g} / \mathrm{ml}$. Blanks consisted of the incubation medium only. Each experiment was performed at least twice and experimental measurements were duplicated within each of the experiments. Values reported are thus the mean and standard deviation of four measurements, unless otherwise stated.

Total proteoglycan content in cartilage was measured at the end of selected experiments. Plugs were blotted dry, weighed, and digested with papain at $65^{\circ} \mathrm{C}$ overnight. The papain solution was prepared by diluting a commercial papain suspension (Sigma Chemical Co., St. Louis, MO, P-3125) 1:50 in a buffer consisting of 0.075 M EDTA and $0.005 \mathrm{M}$ cysteine $\cdot \mathrm{HCl}$. The $\mathrm{pH}$ of this solution was adjusted to 6.5 with $1 \mathrm{~N} \mathrm{NaOH}$. $1.0 \mathrm{ml}$ of this solution was added to each explant. After digestion the concentration of sulfated glycosaminoglycans (GAGS) in the medium was measured by the DMB assay as described above. The proteoglycan content was expressed as micrograms of glycosaminoglycans per milligram of wet weight cartilage. DMB assays of the total digests showed $35.5 \pm 6.0 \mu \mathrm{g}$ of PG (GAGS)/mg of bovine cartilage and $30.9 \pm 1.5 \mu \mathrm{g}$ of PG (GAGS)/mg of normal human cartilage.

Interaction of thrombin with cartilage. The interaction of thrombin with cartilage explants was measured with ${ }^{125} \mathrm{I}$-labeled thrombin. The 
explants were incubated $24 \mathrm{~h}$ at $37^{\circ} \mathrm{C}$ with the labeled protein at various concentrations $(0-10 \mu \mathrm{M})$ in modified Dulbecco's medium. They were then washed twice, and counted with a gamma scintillation counter. Reversibility was assessed by the addition of the unlabeled protein at a high concentration ( $10 \mu \mathrm{M})$ after the binding of the radiolabeled protein $(1.0 \mu \mathrm{M})$ had reached equilibrium, as inferred from measurements of the time course of binding. Binding capacities and affinities were evaluated by least-squares, nonlinear regression analyses (36) using the NONLIN module of SYSTAT (SYSTAT Inc., Evanston, IL). The program provided the mean values of the parameters \pm SEM.

Analysis of synovial fluids for levels of several plasma proteins and covalent complexes of thrombin and Factor Xa with antithrombin III. ELISA assays for numerous plasma coagulation and fibrinolytic zymogens and inhibitors were performed by conventional techniques. Results were compared to those obtained with pooled normal human plasma, used as a reference standard. Sandwich ELISA assays for complexes of antithrombin III with thrombin and Factor Xa were performed as described elsewhere (37) using 96-well Falcon plates (Becton Dickinson) that were precoated with either affinity-purified sheep anti-human thrombin or anti-human Factor $\mathrm{X}$ antibodies by incubation for either $2 \mathrm{~h}$ at $22^{\circ} \mathrm{C}$ or overnight at $4^{\circ} \mathrm{C}$. The plates were blocked with $2 \%$ bovine serum albumin. Standard samples, made up in PBS (136 mM sodium chloride, $2.6 \mathrm{mM}$ potassium chloride, $10 \mathrm{mM}$ disodium hydrogen phosphate, $1.7 \mathrm{mM}$ potassium dihydrogen phosphate, $\mathrm{pH} 7.4$ ), supplemented with $1 \%$ bovine serum albumin, and the synovial fluid samples (diluted 1:200 for the Factor Xa-antithrombin III assay and diluted $1: 4,000$ for the thrombin-antithrombin III assay) were then incubated in the wells for $2 \mathrm{~h}$ at $22^{\circ} \mathrm{C}$. The fluids were then discarded and the wells were washed four times with PBS containing $0.5 \%$ ( vol/vol) Tween 20 (PBS-Tween 20). Diluted, affinity purified, anti-human antithrombin III-horseradish peroxidase-conjugated antibody was added and incubated for $2 \mathrm{~h}$ at $22^{\circ} \mathrm{C}$. The wells were again washed four times with PBS-Tween 20 buffer and once with $\mathrm{H}_{2} \mathrm{O}$. Then a 100- $\mu$ l aliquot of a solution of ortho-phenylenediamine $(0.4 \mathrm{mg} / \mathrm{ml}$ in $12 \mathrm{mM}$ citric acid, $48 \mathrm{mM}$ sodium phosphate, $0.03 \% \mathrm{H}_{2} \mathrm{O}_{2}, \mathrm{pH} 5.0$ ) was added and color development was monitored in a Titertek Twinreader (Flow Laboratories) at $450 \mathrm{~nm}$. After the color had sufficiently developed, the reactions were stopped by the addition of $2.5 \mathrm{M} \mathrm{H}_{2} \mathrm{SO}_{4}(50 \mu$ l per well $)$ and plates were read at $492 \mathrm{~nm}$. Levels of enzyme-inhibitor complexes were quantified by reference to standard curves generated with purified antithrombin III-enzyme complexes. Samples were also analyzed with nonimmune sheep IgG used in place of the capture antibodies, and no positive signals were observed.

Statistical analysis. Results were analyzed with regard to statistical significance by either the Student's unpaired two-tail $t$ test or the FisherBehrens test.

\section{Results}

Proteoglycan release from cartilage after treatment with clotting and fibrinolytic proteases. The enzymes thrombin, Factor $\mathrm{Xa}$, plasmin, tissue plasminogen activator, activated protein $\mathrm{C}$, and urokinase were separately incubated with normal bovine and human cartilage specimens as well as arthritic human cartilage specimens for $24 \mathrm{~h}$ at $37^{\circ} \mathrm{C}$. The proteoglycan contents of the media then were measured. The results ( $\mu \mathrm{g}$ proteoglycan released per $\mathrm{mg}$ of wet weight of cartilage) are presented in Table I. As the data indicate, thrombin was clearly the most active enzyme tested. Samples treated with thrombin released 5.4 to $10.2 \mu \mathrm{g} / \mathrm{mg}$ cartilage, depending on the source of cartilage (Table I, Thrombin). Controls yielded about $1.5 \mu \mathrm{g} / \mathrm{mg}$ (Table I, Buffer). The active site of thrombin was required, since active-site-blocked thrombin gave control values (Table I, Thrombin $[P P A-C K]$. The thrombin concentration indicated in Table $\mathrm{I}(100 \mathrm{nM})$ is about $25 \%$ of the potential which could be gener-
Table I. The Effect of Coagulation and Fibrinolytic Enzymes on Proteoglycan Release ( $\mu \mathrm{g} / \mathrm{mg}$ Cartilage/24 h) in the Presence of Calcium

\begin{tabular}{lccccc}
\hline & \multicolumn{2}{c}{ Normal cartilage } & & \multicolumn{2}{c}{ Diseased cartilage } \\
\cline { 2 - 3 } \cline { 6 - 6 } \multicolumn{1}{c}{ Enzymes } & \multicolumn{1}{c}{ Bovine } & Human & & \multicolumn{1}{c}{ RA } & \multicolumn{1}{c}{ OA } \\
\hline Buffer & $1.5 \pm 0.4$ & $1.8 \pm 0.2$ & & $1.2 \pm 0.4$ & $1.9 \pm 0.3$ \\
Thrombin* & $* * 7.7 \pm 0.3$ & $* * 5.4 \pm 0.2$ & & $* * 5.3 \pm 1.2$ & $* * 10.2 \pm 1.4$ \\
Thrombin* & & & & \\
$\quad$ (PPA-CK) & $1.3 \pm 0.4$ & $1.6 \pm 0.4$ & & - & $1.95 \pm 0.3$ \\
Factor Xa $^{\ddagger}$ & $2.1 \pm 0.7$ & $1.9 \pm 0.5$ & $* * * 3.0 \pm 0.2$ & $* * 4.12 \pm 0.5$ \\
Plasmin $^{1}$ & $1.7 \pm 0.1$ & $1.8 \pm 0.1$ & & $* * 3.6 \pm 0.4$ & $* * 6.1 \pm 0$ \\
tPA $^{\S}$ & $1.2 \pm 0.3$ & $2.0 \pm 0.3$ & & - & $2.1 \pm 0.1$ \\
APC $^{\S}$ & $1.4 \pm 0.1$ & $1.7 \pm 0.2$ & & - & $1.7 \pm 0$ \\
Urokinase $^{\|}$ & 1.5 & - & & - & - \\
\hline
\end{tabular}

* $100 \mathrm{nM} ; \quad+10 \mathrm{nM} ; \quad \$ 50 \mathrm{nM} ; \quad$ " 200 Plough units/ml. tPA and APC, tissue plasminogen activator and activated protein $C$, respectively. Means $( \pm S D)$ were from 4-8 readings per data set. Statistical comparisons were made relative to the buffer control by two-tail unpaired $t$ tests $(* * P<0.005 ; \quad * * * P<0.05)$.

ated from prothrombin in rheumatoid synovial fluid and $32 \%$ of that in osteoarthritis synovial fluids (the prothrombin levels in the two fluids are 29 and $22 \%$ of the plasma level $(1,400$ $\mathrm{nM})$, Table II). Results with Factor Xa and plasmin were marginal in normal cartilage but positive with diseased cartilages, where values ranging from 3.0 to $6.1 \mu \mathrm{g} / \mathrm{mg}$ cartilage were found (lines 4 and 5). Cartilage specimens incubated with tissue plasminogen activator (tPA), activated protein C (APC) and urokinase, liberated control levels.

Changes in wet weight over the 24-h incubation period also were determined for all cartilage specimens and enzymes. Normal human and bovine cartilages incubated with buffer typically lost $0.4-0.7 \%$ of their initial weight overnight. Specimens exposed to the enzymes showed weight losses ranging from $1.4-10.0 \%$ (thrombin); $2.4-3.1 \%$ (Factor $\mathrm{Xa}$ ) and $3.0-4.4 \%$ (plasmin). The other enzymes did not yield weight losses significantly different from control levels. Diseased cartilages exhibited losses in weight also, although the changes were not identical to those obtained with normal tissues. In RA cartilage, weight losses of control specimens varied from $0.4-6.3 \%$, whereas those obtained with the various enzymes were $10-$ $15 \%$ (thrombin), $13-18 \%$ (plasmin), and 12.5-18\% (Factor $\mathrm{Xa})$. The one specimen of OA cartilage analyzed for weight loss showed no change with buffer; $8 \%$ with thrombin; $5 \%$ with Factor $\mathrm{Xa}$; and $21 \%$ with plasmin.

The degradative potential of thrombin, plasmin and Factor $X a$ were further analyzed by incubation of the enzymes (in the presence or absence of $\mathrm{Ca}^{2+}$ ) with samples of cartilage previously subjected to freeze-thaw cycles or heated at $65^{\circ} \mathrm{C}$ as described in Methods. These experiments were performed to determine whether the activities of the enzymes were $\mathrm{Ca}^{2+}$ dependent; are expressed through secondary effects on latent metalloproteinases in the cartilage; or require the participation of viable chondrocytes. The results, (Fig. 1 ) indicate that thrombin $(0.1 \mu \mathrm{M})$ clearly induces proteoglycan release (up to 8.7 $\mu \mathrm{g} / \mathrm{mg}$ wet ) from control, freeze-thawed and heated specimens. Plasmin and Factor $\mathrm{Xa}$ at the concentrations used, elicited less 
Table II. Antigens of Coagulation and Fibrinolysis in Synovial Fluids of Rheumatoid and Osteoarthritis

\begin{tabular}{|c|c|c|c|c|c|c|}
\hline \multirow[b]{2}{*}{ Protein } & \multicolumn{2}{|c|}{ RA } & \multicolumn{2}{|c|}{$\mathrm{OA}$} & \multicolumn{2}{|c|}{ Normal } \\
\hline & Mean & $P$ & Mean & $P$ & Mean & $P$ \\
\hline AT-Xa* & $3 \pm 1$ & .081 & $0.17 \pm .05$ & .224 & $0.56 \pm .27$ & .048 \\
\hline AT-IIa & $42 \pm 14$ & .029 & $4.1 \pm 1.3$ & .035 & $0.98 \pm .40$ & .039 \\
\hline $\mathrm{PGN}^{\ddagger}$ & $16 \pm 4$ & .006 & $16 \pm 2$ & .000 & $2 \pm 2$ & .998 \\
\hline vWF & $17 \pm 6$ & .027 & $3 \pm 1$ & .343 & $2 \pm 1$ & .037 \\
\hline F.X & $28 \pm 3$ & .000 & $26 \pm 2$ & .000 & $8 \pm 2$ & .562 \\
\hline II & $29 \pm 6$ & .011 & $22 \pm 3$ & .028 & $7 \pm 4$ & .318 \\
\hline PS & $32 \pm 6$ & .001 & $25 \pm 3$ & .001 & $7 \pm 3$ & .289 \\
\hline F.XI & $37 \pm 5$ & .000 & $27 \pm 2$ & .000 & $4 \pm 2$ & .069 \\
\hline HCII & $40 \pm 10$ & .006 & $22 \pm 3$ & .023 & $6 \pm 4$ & .087 \\
\hline PC & $41 \pm 10$ & .006 & $14 \pm 3$ & .164 & $8 \pm 3$ & .017 \\
\hline F.IX & $44 \pm 12$ & .093 & $19 \pm 3$ & .796 & $21 \pm 4$ & .072 \\
\hline ATIII & $45 \pm 5$ & .007 & $46 \pm 4$ & .007 & $12 \pm 7$ & .831 \\
\hline PCI & $54 \pm 5$ & .000 & $58 \pm 4$ & .000 & $6 \pm 5$ & .524 \\
\hline$\alpha 1 \mathrm{AT}$ & $56 \pm 7$ & .204 & $42 \pm 3$ & .963 & $41 \pm 8$ & .091 \\
\hline$\beta 2 \mathrm{GP1}$ & $78 \pm 4$ & .003 & $71 \pm 2$ & .010 & $38 \pm 7$ & .158 \\
\hline
\end{tabular}

Synovial fluids from 11 patients with RA and 23 with OA at joint replacement surgery, and 4 normals (cadaver), were collected into anticoagulant. Samples were assayed by ELISA or RID (radial immunodiffusion) for the species indicated above. Results are shown as mean \pm SEM, (percent of normal human plasma; AT-Xa, AT-IIa are nM). $P$ values ( $t$ test) in RA and OA are compared to normal, $P$ values at the right are for RA compared with OA. * Concentrations of AT-Xa and AT-IIa are provided in units of nM. ${ }^{\ddagger}$ Concentrations of PGN and the proteins listed below it are given as percent of the levels in normal plasma.

prominent, but nonetheless, positive responses in the same specimens. These data do not definitely indicate whether the effect of Factor $\mathrm{Xa}$ and plasmin are $\mathrm{Ca}^{2+}$ dependent, but clearly show that the effect of thrombin is not. The results also suggest that thrombin acts directly and thus does not require the participation of endogenous zymogens or chondrocytes to elicit degradation.

Normal cartilage degradation with prothrombin plus prothrombinase components. Because exogenous purified thrombin induced proteoglycan release, experiments were performed to

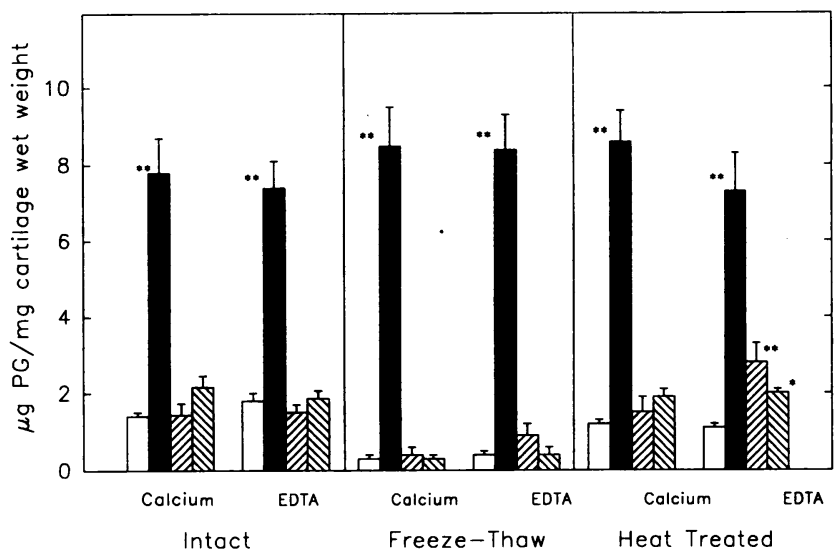

Figure 1. Cartilage proteoglycan release induced by thrombin, Factor $\mathrm{Xa}$, or plasmin. This figure indicates proteoglycan release from intact, frozen/thawed, or heated bovine cartilage incubated for $24 \mathrm{~h}$ with ( $\square)$ thrombin $(0.1 \mu \mathrm{M}),(\square)$ plasmin $(0.1 \mu \mathrm{M})$, and ( $\square)$ Factor Xa (10 $\mathrm{nM}$ ) in the presence of $5 \mathrm{mM} \mathrm{CaCl}_{2}$ or $10 \mathrm{mM}$ EDTA. Values are the mean and SD of eight measurements. Asterisks denote release significantly above control level ( $\left.{ }^{* *} P<0.005,{ }^{*} P<0.05\right)$. ( $\square$ ) Buffer. determine whether degradation of normal human cartilage would occur in the presence of various combinations of the prothrombinase complex (Factor $\mathrm{Xa}$, Factor V, phospholipid vesicles, and $\mathrm{Ca}^{2+}$ ) plus prothrombin (Factor II). Cartilage degradation occurred when all of the components were present, but only marginally or not at all under conditions in which either the substrate (prothrombin) or one or more of the components of the enzymatic complex were lacking (Fig. 2). The activity of the prothrombinase complex did not require added

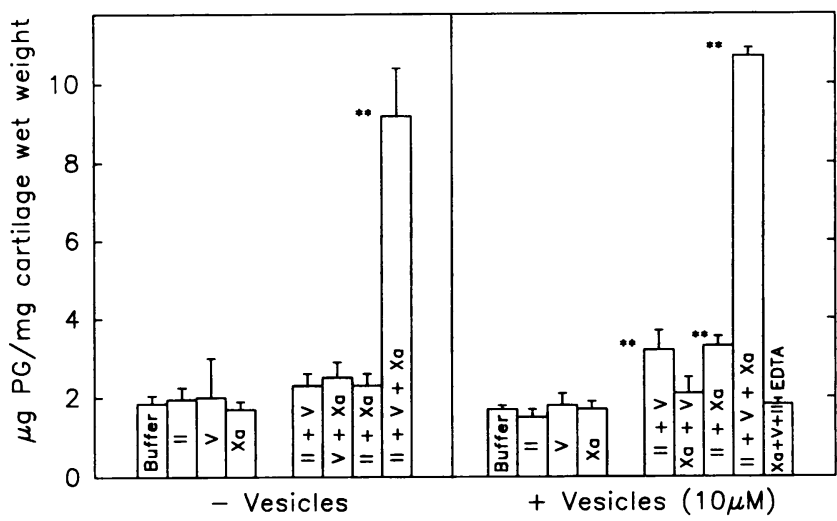

Figure 2. Cartilage proteoglycan release by various combinations of prothrombin and the components of prothrombinase. This figure indicates the effects of various combinations of the components of the prothrombinase complex ( $10 \mathrm{nM}$ Factor $\mathrm{Xa}, 10 \mathrm{nM}$ Factor V, $5 \mathrm{mM}$ $\mathrm{CaCl}_{2}$, plus [right panel] or minus [left panel] $10 \mu \mathrm{M}$ phospholipid vesicles) with prothrombin $(0.1 \mu \mathrm{M})$ on proteoglycan release from human cartilage. The data indicate that physiological activator plus prothrombin induce proteoglycan release. $(* * P<0.005)$ 

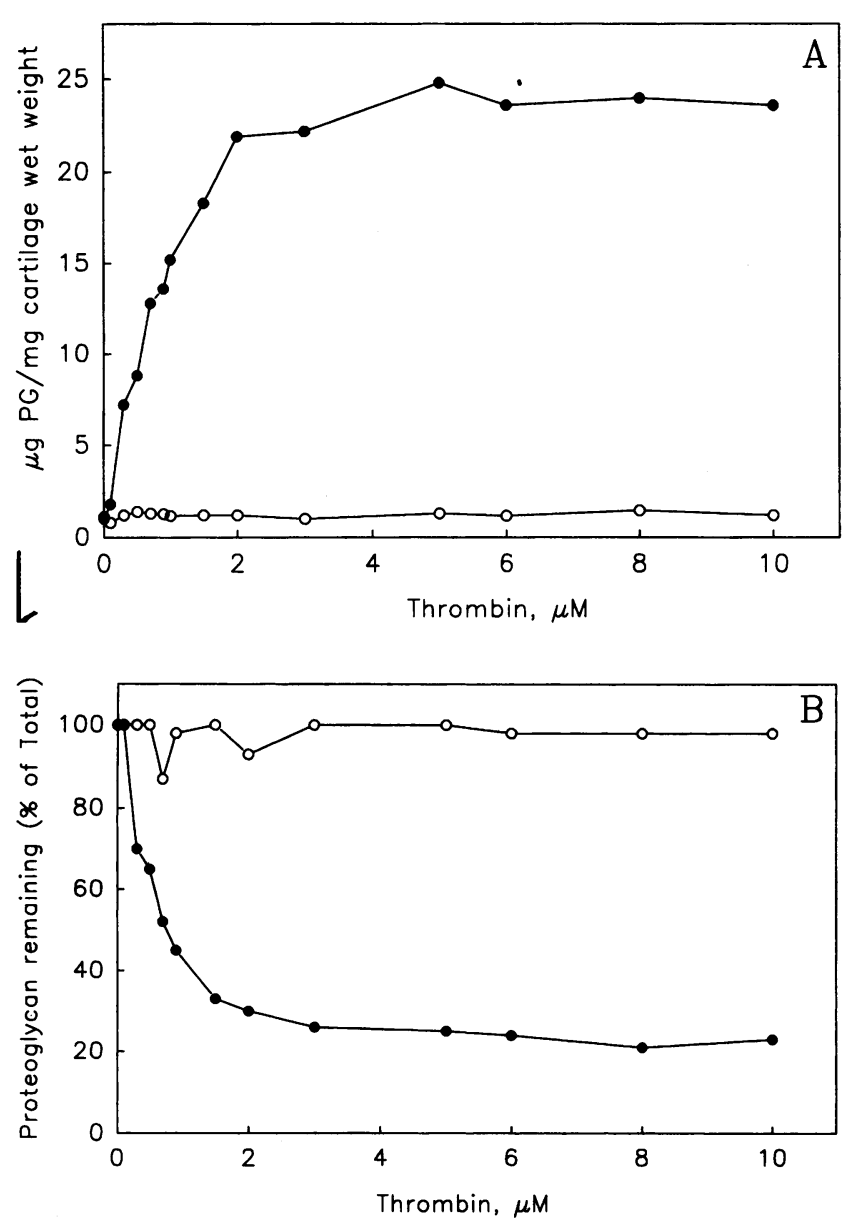

Figure 3. Thrombin concentration dependence of proteoglycan release and residual proteoglycan from normal human (cadaver) cartilage. Cartilage explants (cadaver) were incubated $24 \mathrm{~h}$ with $0-10 \mu \mathrm{M}$ thrombin $(\bullet)$ or PPA-CK thrombin $(O)(A)$. Levels of proteoglycans in the media were measured by the DMB assay. Cartilage explants after incubation with 0-10 $\mu \mathrm{M}$ thrombin ( $\bullet$ ) or 0-10 $\mu \mathrm{M}$ PPA-CK thrombin (O) were digested with papain at $65^{\circ} \mathrm{C}$ overnight $(B)$. The residual proteoglycan levels were measured by the DMB assay, and results are expressed as percent of total cartilage proteoglycans.

phospholipid vesicles, suggesting that the cartilage may have provided the equivalent of a catalytic surface for the activation of prothrombin. The response, like prothrombinase activity, was $\mathrm{Ca}^{2+}$ dependent as indicated by the lack of response in the presence of EDTA. Bovine cartilage gave essentially identical results (not shown). These data show that in the presence of cartilage, the combination of prothrombin and prothrombinase, which yields active thrombin in a $\mathrm{Ca}^{2+}$-dependent process, induces $\mathrm{Ca}^{2+}$-dependent cartilage degradation.

Thrombin dose response and time course of proteoglycan release. The results of 24-h incubations of human (cadaver) cartilage with thrombin $(0-10 \mu \mathrm{M})$ or thrombin blocked at the active site by PPA-CK are shown in Fig. $3 \mathrm{~A}$. Proteoglycan release was saturable; half-maximal proteoglycan release occurred at $0.9 \mu \mathrm{M}$ thrombin; and at saturation $24 \mu \mathrm{g}$ of proteoglycan was released per mg of cartilage. No release above background occurred in the presence of PPA-CK thrombin.

The residual proteoglycan content of cartilage after exposure

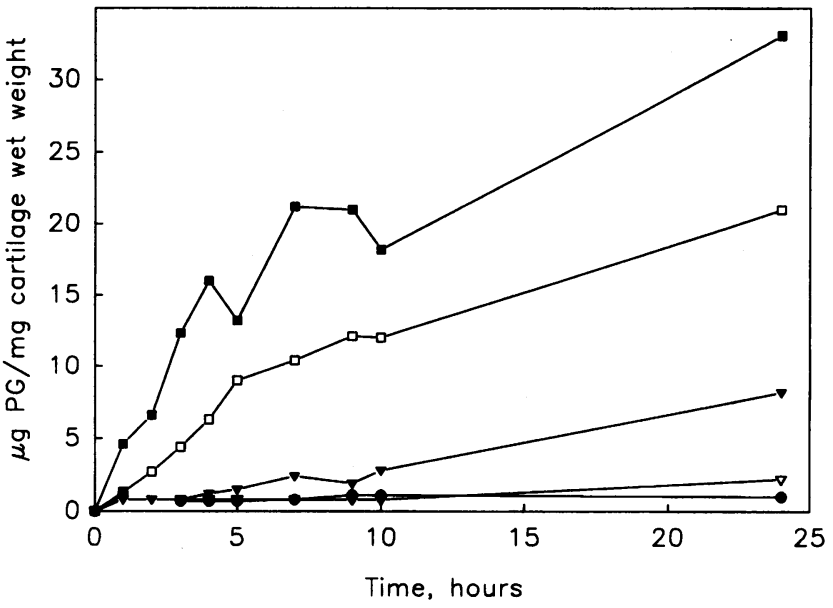

Figure 4. Time course of proteoglycan release from bovine cartilage incubated with thrombin $(0-10 \mu \mathrm{M})$. At intervals samples of the media were removed and proteoglycan contents were measured by the DMB assay after exposure to buffer $(\bullet)$ or thrombin at concentrations of 50 $\mathrm{nM}(\nabla), 100 \mathrm{nM}(\nabla), 1 \mu \mathrm{M}(\square)$, and $10 \mu \mathrm{M}(\square)$.

of the explants to thrombin was assayed by subsequent total digestion with papain and subsequent proteoglycan measurements as described in the Methods. The results (Fig. $3 B$ ) indicate a concentration dependence similar to that for release and a plateau at $\sim 20 \%$ residual proteoglycan. Whether the residual amount that remained represents a subpopulation relatively resistant to the effects of thrombin was not investigated.

The time dependence of proteoglycan release from bovine cartilage is shown in Fig. 4. Lower doses of thrombin $(0.05$ and $0.1 \mu \mathrm{M}$ ) caused a slow progressive accumulation of proteoglycans in the medium, whereas higher doses of the enzyme ( 1.0 and $10 \mu \mathrm{M}$ ) caused relatively rapid cartilage breakdown and proteoglycan release.

Thrombin binding to cartilage. Bovine cartilage explants were incubated with radiolabeled thrombin or active-siteblocked thrombin (PPA-CK thrombin) at various concentrations for $24 \mathrm{~h}$. Concentration-dependent binding was apparent in both cases, but more binding occurred with the PPA-CK thrombin (Fig. 5). With either form of thrombin, nonlinear regression analysis (SYSTAT-Non-LIN) gave a best fit for a model of a single class of binding sites. According to the model, represented by the equation, Bound $=$ Bound $_{\max }[\mathrm{IIa}] /\left(K_{\mathrm{d}}\right.$ $+[$ III $]$ ), the binding capacities $\left(B_{\max }\right.$ ) were $1233 \pm 55 \mathrm{ng} / \mathrm{mg}$ of unmodified thrombin per $\mathrm{mg}$ of bovine cartilage, and $4117 \pm 66 \mathrm{ng}$ PPA-CK thrombin per $\mathrm{mg}$ of bovine cartilage. Corresponding $K_{\mathrm{d}}$ values were $4.4 \pm 0.4 \mu \mathrm{M}$ and $4.2 \pm 0.12 \mu \mathrm{M}$. The results obtained with human cartilage were $B_{\max }=820 \pm 70$ $\mathrm{ng} / \mathrm{mg} ; K_{\mathrm{d}}=7.0 \pm 1.0 \mu \mathrm{M}$ for unmodified thrombin and $\mathrm{B}_{\max }=2200 \pm 200 \mathrm{ng} / \mathrm{mg}$ and $K_{\mathrm{d}}=4.3 \pm 0.7 \mu \mathrm{M}$ for PPA-CK thrombin.

The difference between the binding of thrombin and PPACK thrombin to cartilage might imply that thrombin can bind to proteoglycan molecules and degrade them, and thereby eliminate potential binding sites. To test this hypothesis, samples of bovine cartilage were preincubated for $24 \mathrm{~h}$ with $1.0 \mu \mathrm{M}$ active thrombin and washed. The binding of unmodified and PPA-CK thrombin were then determined with the pretreated cartilage specimens. Pretreatment of cartilage did not significantly affect 


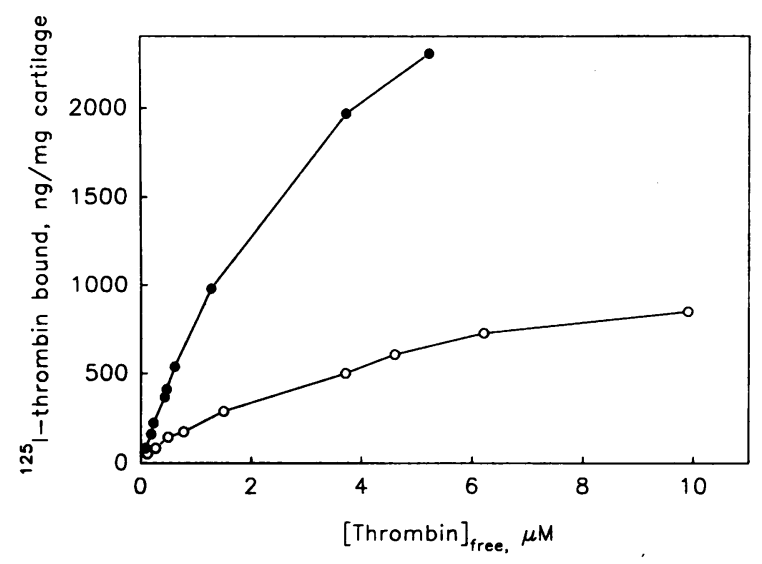

Figure 5. Interaction of ${ }^{125} \mathrm{I}$-thrombin with bovine cartilage. Cartilage explants were separately incubated for $24 \mathrm{~h}$ at $37^{\circ} \mathrm{C}$ with $0-10 \mu \mathrm{M}^{125} \mathrm{I}$ thrombin (O) or ${ }^{125} \mathrm{I}$-PPA-CK thrombin $(\bullet) .{ }^{125} \mathrm{I}$-thrombin bound was calculated and data were analyzed by nonlinear regression analysis using SYSTAT. $B_{\max }$ and $K_{\mathrm{d}}$ values were $1233 \pm 33 \mathrm{ng}$ thrombin/mg cartilage, $4.4 \pm 0.4 \mu \mathrm{M}$ (thrombin); and $4117 \pm 66 \mathrm{ng}$ PPA-CK thrombin $/ \mathrm{mg}$ cartilage $4.2 \pm 0.12 \mu \mathrm{M}$ (PPA-CK thrombin).

the binding of either unmodified thrombin $\left(B_{\max }=1769 \pm 126\right.$ $\left.\mathrm{ng} / \mathrm{mg}, K_{\mathrm{d}}=6.8 \pm 0.9 \mu \mathrm{M}\right)$ or PPA-CK thrombin $\left(\mathrm{B}_{\max }\right.$ $\left.=4257 \pm 424 \mathrm{ng} / \mathrm{mg}, K_{\mathrm{d}}=5.5 \pm 0.9 \mu \mathrm{M}\right)$. Thus, the difference in capacity for thrombin compared to PPA-CK thrombin can not be attributed to degradation of the cartilage and present data do not offer an explanation for the difference.

Time course and reversibility of ${ }^{125}$ I-labeled thrombin binding to bovine cartilage. Binding equilibria for thrombin and PPA-CK thrombin $(1.0 \mu \mathrm{M})$ were established within $2 \mathrm{~h}$, and half-maximal binding occurred in $\sim 30 \mathrm{~min}$ (Fig. 6). Excess unlabeled thrombin $(10 \mu \mathrm{M})$ added at equilibrium reversed the binding of the radiolabeled proteins, and after $24 \mathrm{~h} \mathrm{33 \%}$ of maximal radioactivity was associated with cartilage explants.

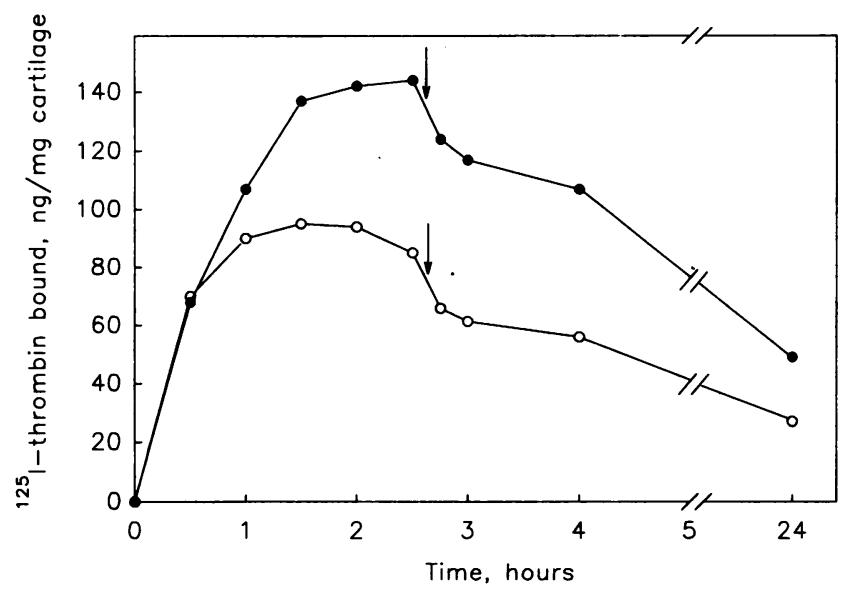

Figure 6. Time course and reversibility of ${ }^{125} \mathrm{I}$-thrombin binding to bovine cartilage. Cartilage explants were incubated with $1 \mu \mathrm{M}^{125} \mathrm{I}$ thrombin (O) or $1 \mu \mathrm{M}^{125}$ I-PPA-CK thrombin ( $\bullet$ ). At intervals plugs were washed, blotted dry, and associated radioactivities were measured. At equilibrium (arrows) unlabeled unmodified thrombin $(10 \mu \mathrm{M})$ was added and the radiolabeled thrombin or PPA-CK-thrombin content was measured at intervals up to $24 \mathrm{~h}$.
The reversal of the binding of PPA-CK thrombin by excess unlabeled PPA-CK thrombin was identical to that accomplished with unmodified thrombin (not shown). Similar data were obtained with human cartilage, although residual thrombin binding was greater $(64 \%)$.

The binding of radiolabeled fibrinogen to bovine cartilage also was investigated. Cartilage specimens were preincubated $24 \mathrm{~h}$ either in buffer or buffer plus thrombin $(0.1 \mu \mathrm{M})$ and then extensively washed prior to the addition of fibrinogen $(3.0 \mu \mathrm{M})$. In spite of extensive washing, the solutions surrounding thrombin-treated cartilage clotted immediately. In addition, the control samples clotted in $2 \mathrm{~h}$. Both the thrombin-treated and control samples were incubated overnight, macroscopic fibrin was removed by extensive washing, and the remaining bound fibrin (ogen) of the explants was determined by gamma scintillation counting. The control specimen bound $116 \pm 3.4 \mathrm{ng}$ fibrin $/ \mathrm{mg}$ cartilage whereas the thrombin treated cartilage specimen bound $208 \pm 45 \mathrm{ng}$ fibrin/mg cartilage. The data suggest that cartilage can bind fibrin(ogen) and that thrombin may enhance the binding.

Levels of coagulation and fibrinolytic zymogens and inhibitors, and covalent thrombin-antithrombin III and Factor $\mathrm{Xa}$ antithrombin III complexes in synovial fluids. To determine whether synovial fluids in arthritic knee joints have the components of the coagulation and fibrinolytic cascades, ELISAs were performed to determine the levels of 13 plasma proteins. In addition, to determine whether the enzymes thrombin and Factor $\mathrm{Xa}$ had been generated from their precursors, the levels of their covalent complexes with antithrombin III were measured. The results of these assays are indicated in Table II, in which results for the individual proteins are expressed as a percent of the values obtained with pooled, normal human plasma. The results for the complexes of Factor $\mathrm{Xa}$ and thrombin are expressed in nanomoles/liter. These latter units were chosen because plasma levels of these complexes are in the picomolar range and relative comparisons to plasma would have obscured comparisons to control synovial fluids. Values were obtained for 11 patients with rheumatoid arthritis, 23 with osteoarthritis, and 4 normal specimens (cadavers). The data indicate that the coagulation zymogens prothrombin, Factor IX, Factor X, and Factor XI are present in rheumatoid fluids at levels ranging from 29 to $44 \%$ of the normal plasma level. Similar, but not identical profiles were found in osteoarthritis fluids. These values indicate that both fluids possess the zymogens which define the coagulation cascade. In addition, with the exception of Factor IX, the levels of the zymogens in both fluids significantly exceed the levels in control fluids. Two coagulation inhibitors, antithrombin III and heparin cofactor II, are also present at levels which significantly exceed control values. Three components associated with the activated protein $\mathrm{C}$ anticoagulation pathway, protein $\mathrm{C}$, protein $\mathrm{S}$, and protein $\mathrm{C}$ inhibitor (PCI), are also present at elevated levels, although protein $\mathrm{C}$ is not significantly elevated in osteoarthritis. Except for von Willebrand factor in osteoarthritis, which was present at $3 \%$ its level in plasma, plasminogen was present at the lowest value ( $16 \%$ of plasma) of all proteins measured in both rheumatoid and osteoarthritis. Its level, in both cases, however, was significantly elevated relative to control (2\% of plasma).

Covalent complexes of thrombin with antithrombin III were significantly elevated relative to controls in both rheumatoid and osteoarthritis. The mean values exceed the mean control 
value by factors of 4.2 and 41 in osteo- and rheumatoid fluids, respectively. Covalent complexes of Factor Xa with antithrombin III were elevated in rheumatoid arthritis and depressed in osteoarthritis compared to controls.

The existence of these complexes clearly indicates that the active enzymes Factor $\mathrm{Xa}$ and thrombin had existed within the synovial fluids of the diseased joints. In addition, the elevated levels of thrombin-antithrombin III complexes suggest that thrombin had been produced at higher rates or for longer periods in arthritic joints compared to controls, especially in rheumatoid arthritis. The data of Table II, in addition to indicating that the synovial fluids in arthritis possess components of coagulation cascade and that thrombin and Factor Xa had been present in these fluids, in most cases distinguish fluids from both diseases from normal fluids and, in some cases, distinguish the two disease fluids from one another. With the exception of the levels of $\alpha_{1}$ antitrypsin and Factor IX, the levels of all the proteins are significantly elevated relative to controls in rheumatoid fluids. In osteo fluids, the levels of von Willebrand Factor and protein $\mathrm{C}$ also are not significantly elevated compared to controls. The levels of von Willebrand Factor and protein $\mathrm{C}$, however, are significantly different from one another when values in fluids from osteo and rheumatoid arthritis are compared. In addition, levels of the covalent complexes of Factor $\mathrm{Xa}$ and thrombin with antithrombin III are both significantly different when compared in the two diseases. Thus, some of these parameters, or collections of them, may be of value not only in identifying arthritis but also distinguishing osteo- from rheumatoid arthritis.

\section{Discussion}

The results of these studies indicate that thrombin, and the combination of prothrombin plus prothrombinase, rapidly induce in vitro release of proteoglycan from both normal and diseased cartilage explants. Factor $\mathrm{Xa}$ and plasmin have similar effects but of a smaller magnitude; and activated protein $\mathrm{C}$, urokinase, and tissue plasminogen activator do not induce measurable effects under the conditions tested. The results also indicate that thrombin saturably and reversibly binds cartilage and equilibrium is established within $2 \mathrm{~h}$. In addition, covalent complexes of Factor $\mathrm{Xa}$ and thrombin with their physiologic inhibitor, antithrombin III, were detected in samples of synovial fluids from OA and RA joints, an observation which suggests a history of extravascular activation of coagulation in these joints. The fluids also contain the zymogens which constitute the coagulation cascade.

Of the enzymes tested, thrombin is the most potent in proteoglycan degradation of normal bovine and human cartilage. A direct effect of thrombin on cartilage is suggested, because the effect is not dependent on $\mathrm{Ca}^{2+}$, chondrocytes, or any intraor extracellular activities. The active site of thrombin is required for proteoglycan degradation, since active site-blocked thrombin has no effect.

Cartilage proteoglycans have a strong affinity for cationic antigens and enzymes, which are able to penetrate articular cartilage in spite of their high molecular weight. Thrombin, which has a molecular weight of 37,400 , is of particular interest in this context, because it, like elastase and cathepsin $\mathrm{G}$, is cationic at physiological $\mathrm{pH}(38,39)$. Whether the cationic properties of human thrombin contribute to its ability to bind and degrade cartilage was not established in these studies, but their importance in these interactions and reactions can be postulated by analogy with results obtained with elastase by Schalkwijk et al. (38), who showed that elimination of positive charge by succinylation attenuated the ability of elastase to promote cartilage degradation. Although thrombin induced proteoglycan release from both normal and diseased cartilage, plasmin and Factor $\mathrm{Xa}$, which are not cationic, elicited clear positive responses only with diseased specimens. These observations are consistent with the views of Schalkwijk et al. (38), who suggested that proteases such as elastase and cathepsin $\mathrm{G}$ mediate degradation at the onset of arthritis when the cartilage is relatively intact and has a high negative fixed-charge density that favours cationic proteases. Their actions presumably cause degradation of proteoglycan and reduction of fixed-charge density in matrix, and thereby facilitate entry of other proteases. We found that total proteoglycan content in diseased cartilage was lower $(19.6 \pm 4 \mu \mathrm{g} \mathrm{PG} / \mathrm{mg}$ in $\mathrm{OA}$ and $13.9 \pm 3 \mu \mathrm{g} \mathrm{PG} / \mathrm{mg}$ in RA) compared to normal $(30.9 \pm 1.5 \mu \mathrm{g} \mathrm{PG} / \mathrm{mg})$. Therefore, this observation may explain the observation that diseased cartilage was considerably more sensitive to plasmin and Factor Xa than normal cartilage, whereas the normal cartilage was degraded as readily as diseased cartilage in the presence of thrombin.

Proteoglycan degradation also was observed when prothrombin plus its physiological activator prothrombinase (Factor $\mathrm{Xa}$, Factor $\mathrm{Va}$, negatively charged phospholipid vesicles, and $\mathrm{Ca}^{2+}$ ) were incubated with normal human or bovine cartilage. Results were notable at a prothrombin level as low as $0.1 \mu \mathrm{M}$ (Fig. 2), which is about $1 / 15$ the physiological level of prothrombin in plasma and about $25 \%$ of that found in synovial fluids in arthritis. Phospholipid vesicles were not crucial, since a similar result was obtained in their absence. This observation suggests that cartilage can provide the catalytic surface for thrombin generation. The response, however, like prothrombinase activity was $\mathrm{Ca}^{2+}$ dependent. The observations with purified prothrombinase components in vitro may be extrapolated to conditions in vivo whereupon plasma proteins and leukocytes enter inflamed joints (8) and thereby may provide components for the assembly of the prothrombin-activating complex and subsequent thrombin generation.

In inflammatory processes, activated leukocytes and endothelium express numerous components of both the coagulation and fibrinolytic pathways $(40,41)$. Products of the coagulation and fibrinolytic reactions act to amplify the inflammatory reactions by attracting more inflammatory cells to the site through the chemotactic activities of thrombin (42), fibrin(ogen) (43), and fibrinogen-derived peptides (44). Inflammatory mediators (TNF, IL-1) released from activated monocytes enhance expression of tissue factor in endothelial cells $(45,46)$. In addition, Factor Xa stimulates release of endothelial cell mitogens (47), and thrombin induces release of growth factor activities from several cell types (48). Thus, these enzymes conceivably might contribute not only to the degradation of cartilage but also to the pathological proliferation of the synovium.

Work by others suggests a role for the fibrinolytic cascade in pathogenesis of RA and OA. The components of fibrinolytic system, plasminogen, plasminogen activators, and plasminogen activator inhibitor type 1 were found in diseased OA and RA cartilage $(49,50)$. Plasmin mediates cartilage degradation in vitro, catalyzes degradation of proteoglycans, and activates la- 
tent metalloproteinases (12-14). Moreover, plasmin derived fibrin degradation products have been detected in the synovium and synovial fluid of patients with RA $(15,16)$. A similar role for coagulation proteases can be postulated from previous results and observations. The nearly universal existence of fibrin in the cartilage and synovial tissue in RA $(8,18)$, and its frequent presence in OA (19), strongly indicates intraarticular activation of the coagulation cascade and generation of thrombin. In addition, Weinberg et al. (17), recently demonstrated in inflamed joints (OA and RA) enhanced expression of procoagulant molecules (fibrinogen, prothrombin, tissue factor, Factor XIII) which could contribute to the local pathology of the inflammation. In addition, Richardson et al. (51), have shown that thrombin, in addition to plasmin, catalyzes proteoglycan degradation in the thoracic aorta of the rabbit.

Our results show not only that components associated with coagulation including thrombin, Factor $\mathrm{Xa}$, and prothrombin plus prothrombinase induce cartilage degradation in vitro, but also that thrombin and Factor $\mathrm{Xa}$ had been present in synovial fluids, as inferred by the presence of enzyme-inhibitor complexes. Together, these observations implicate intra-articular activation of the coagulation cascade as a potential contributor to cartilage destruction in arthritis.

Because anticoagulant therapy can both attenuate activation of coagulation and modify immunologically mediated inflammation $(52,53)$, agents capable of preventing the intraarticular activation of coagulation may be useful in diminishing cartilage destruction in arthritis. In addition, the products of coagulation (and possibly fibrinolysis) in synovial fluids may have diagnostic value. For example, the elevated levels of thrombin-antithrombin III were clearly markers for arthritis, particularly rheumatoid arthritis, and some of the parameters indicated in Table II not only correlated with arthritis but also distinguished the two types of arthritis.

\section{Acknowledgments}

The authors wish to thank Ms. Kim Clark for typing and Mr. Tom Abbott for preparation of figures and tables.

This study was supported by grants from the Medical Research Council of Canada (DG 309 and MA 9781), the Heart and Stroke Foundation of Ontario and the Arthritis Society of Canada.

\section{References}

1. Rodnan, G. P., and H. R. Schumacher. 1983. Primer on the Rheumatic Diseases. Arthritis Foundation, Toronto. 238 pp.

2. Harris, E. D., Jr. 1989. The clinical features of rheumatoid arthritis. In Textbook of Rheumatology. W. N. Kelly, E. D., Jr. Harris, S. Rudy, and C. B. Sledge, editors. Philadelphia. 943-974.

3. Cooke, T. D. V., and R. A. Scudamore. 1989. Studies in the pathogenesis of rheumatoid arthritis. Immunogenetic associations. Br. J. Rheumatol. 28:243250.

4. Murphy, G., A. J. P. Docherty, R. M. Hembry, and J. J. Reynolds. 1991. Metalloproteinases and tissue damage. Br. J. Rheumatol. 30 (suppl. 1):25-31

5. Vaes, G. 1980. Cellular secretion and tissue breakdown. Cell-to-cell interactions in the secretion of enzymes of connective tissue breakdown, collagenase and proteoglycan degrading neutral proteases. A review. Agents Actions. 10:474485.

6. Gavrilovic, J., R. M. Hembry, J. J. Reynolds, and G. Murphy. 1987. Tissue inhibitor of metalloproteinases (TIMP) regulates extracellular type I collagen degradation by chondrocytes and endothelial cells. J. Cell. Sci. 87:357-362.

7. Hayakawa, T., K. Yamashita, S. Kodama, H. Iwata, and K. Iwata. 1991. Tissue inhibitor of metalloproteinases and collagenase activity in synovial fluid of human rheumatoid arthritis. Biomed. Res. 12(3):169-173.
8. Kelly, W. N., E. D. Harris Jr., S. Ruddy, and C. B. Sledge. 1989. The Inflammatory Response. In Textbook of Rheumatology, Third edition. 241-415. 9. Shinmei, M., K. Masuda, T. Kikuchi, and Y. Shimomura. 1989. Interleukin1, tumor necrosis factor, and interleukin- 6 as mediators of cartilage destruction. Semin. Arthritis Rheum. 18:27-32.

10. Cush, J. J., and P. E. Lipsky. 1991. Cellular basis for theumatoid inflammation. Clin. Orthop. Relat. Res. 265:9-22.

11. Virca, G. D., R. K. Mallya, M. B. Pepys, and H. P. Schnebli. 1984. Quantitation of human leukocyte elastase, cathepsin G, alpha ${ }_{2}$-macroglobulin and

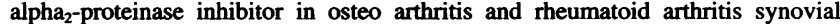
fluids. Adv. Exp. Med. Biol. 167:345-353.

12. Martel-Pelletier, J., J. M. Cloutier, and J. P. Pelletier. 1989. Possible role of plasmin and cathepsin B activating metalloproteinase in human OA joints. Trans. Orthop. Res. Soc. 14:306.

13. Tyler, J. A. 1991. Cartilage degradation. In Cartilage: Molecular Aspects. B. Hall and S. Newman, editors. CRC Press. 213-254.

14. Mochan, E., and T. Keler. 1984. Plasmin degradation of cartilage proteoglycan. Biochim. Biophys. Acta. 800:312-315.

15. Gromsen, J., R. B. N. Andersen, and C. Feddersen. 1971. Fibrinogenfibrin breakdown products in pathologic synovial fluids. An immunologic study. Arthritis Rheum. 14:503-512.

16. Jespersen, J., E. J. P. Brommer, F. Haverkate, and W. Nieuwenhuizen. 1989. Degradation products of fibrin and of fibrinogen in synovial fluid and in plasma of patients with rheumatoid arthritis. Fibrinolysis. 3:183-196.

17. Weinberg, J. B., A. M. M. Pippen, and C. S. Greenberg. 1991. Extravascular fibrin formation and dissolution in synovial tissue of patients with osteo arthritis and rheumatoid arthritis. Arthritis Rheum. 34:996-1005.

18. Clemmensen, I., B. Holund, and R. B. Andersen. 1983. Fibrin and fibronectin in rheumatoid synovial membrane and rheumatoid synovial fluid. Arthritis Rheum. 26:479-485.

19. Rosenberg, L. C. 1991. Structure and function of dermatan sulfate proteoglycans in articular cartilage. In Articular Cartilage and Osteoarthritis. Workshop Conference. Hoechst Werk Kalle-Albert. K. E. Kuettner, R. S. Schleyerbach, J. G. Peyron, and V. C. Hascall, editors. Raven Press, New York. 45-63.

20. Flier, J. S., and K. H. Underhill. 1992. Molecular and cellular biology of blood coagulation. N. Engl. J. Med. 326:800-806.

21. Altieri, D. C., and T. S. Edgington. 1989. Sequential receptor cascade for coagulation proteins on monocytes. Constitutive biosynthesis and functional prothrombinase activity of a membrane form of factor V/Va. J. Biol. Chem. 264:2969-2972.

22. Van Dam-Mieras, M. C. E., A. D. Muller, W. A. van Deijk, and H. C. Hemker. 1985. Clotting factors secreted by monocytes and macrophages: analytical considerations. Thromb. Res. 37:9-19.

23. Tracy, P. B. 1987. Cellular involvement in coagulation: workshop report. Proteases in Biological Control and Biotechnology. Alan R. Liss, Inc., New York. 249-253.

24. Miletich, J. P., G. J. Broze, and P. W. Majerus. 1981. Purification of human coagulation factors II, IX, and X using sulfated dextran beads. Methods Enzymol. 80:221-228.

25. Bajzar, L., J. C. Fredenburgh, and M. E. Nesheim. 1990. Activated protein C-mediated enhancement of tissue-type plasminogen activator-induced fibrinolysis in a cell-free system. J. Biol. Chem. 265:16948-16954.

26. Nesheim, M. E., J. A. Katzmann, P. B. Tracy, and K. G. Mann. 1981 Factor V. Methods Enzymol. 80:249-274.

27. Castellino, F. J., and J. R. Powell. 1981. Human plasminogen. Methods Enzymol. 80:365-379.

28. Wiman, B., and D. Collen. 1977. Purification and characterization of human antiplasmin, the fast-acting plasmin inhibitor in plasma. Eur. J. Biochem. 78:19-26.

29. Krishnaswamy, S., W. R. Church, M. E. Nesheim, and K. G. Mann. 1987. Activation of human prothrombin by human prothrombinase. Influence of Factor Va on the Reaction Mechanism. J. Biol. Chem. 262:3291-3299.

30. Lundblad, R. L., H. S. Kingdon, and K. G. Mann. 1976. Thrombin. Methods Enzymol. 45:156-176.

31. Straughn, W., and R. H. Wagner. 1966. A simple method for preparing fibrinogen. Thromb. Diath. Haemorrh. 16:198-206.

32. Nesheim, M. E. 1983. A simple rate law that describes the kinetics of the heparin-catalyzed reaction between antithrombin III and thrombin. J. Biol. Chem. 258:14708-14717.

33. Bloom, J. W., M. E. Nesheim, and K. G. Mann. 1979. Phospholipid binding properties of bovine factor $\mathrm{V}$ and factor Va. Biochemistry. 18:44194425.

34. Herman, J. H., D. Greenblatt, R. C. Khosla, and A. M. Appel. 1984 Cytokine modulation of chondrocyte proteinase release. Arthritis Rheum. 27:7991.

35. Farndale, R. W., D. J. Buttle, and A. J. Barrett. 1986. Improved quantitation and discrimination of sulphated glycosaminoglycans by use of dimethylmethylene blue. Biochim. Biophys. Acta. 883:173-177. 
36. Marquardt, D. W. 1963. An algorithm for least-squares estimation of nonlinear parameters. J. Soc. Ind. Appl. Math. 11:431-441.

37. Scully, M. F., C. H. Toh, H. Hoogendorn, R. P. Manuel, M. E. Nesheim, S. Solymoss, and A. R. Giles. 1993. Activation of protein C and its distribution between its inhibitors, protein $\mathrm{C}$ inhibitor, alpha ${ }_{1}$-antitrypsin and alpha ${ }_{2}$-macroglobulin, in patients with disseminated intravascular coagulation. Thromb. Haemostasis. 69:448-453.

38. Schalkwijk, J., L. A. B. Joosten, W. B. van den Berg, and L. B. A. van de Putte. 1988. Degradation of cartilage proteoglycans by elastase is dependent on charge-mediated interaction. Rheumatol. Int. 8:27-33.

39. Mann, K. G., J. Elion, R. J. Butkowski, M. Downing, and M. E. Nesheim. 1981. Prothrombin. Methods Enzymol. 80:286-302.

40. Harlan, J. M. 1987. Consequences of leukocyte-vessel wall interactions in inflammatory and immune reactions. Semin. Thromb. Hemostasis 13:434-444.

41. Vassalli, J. D., J. M. Dayer, A. Wohlwend, and D. Belin. 1984. Concomitant secretion of prourokinase and of a plasminogen activator-specific inhibitor by cultured human monocytes-macrophages. J. Exp. Med. 159:1653-1668.

42. Bizios, R., L. Lai, J. W. Fenton, and A. B. Malik. 1986. Thrombin-induced chemotaxis and aggregation of neutrophils. J. Cell. Physiol. 128:485-490.

43. Colvin, R. B. 1986. Wound healing processes in hemostasis and thrombosis. In Vascular Endothelium in Hemostasis and Thrombosis. M. A. Gimbrone Jr., editor. Churchill Livingstone, New York. 250 pp.

44. Richardson, D. L., D. S. Pepper, and A. B. Kay. 1976. Chemotaxis for human monocytes by fibrinogen-derived peptides. Br. J. Haematol. 32:507-513.

45. Nawroth, P. P., and D. M. Stern. 1986. Modulation of endothelial hemostatic properties by tumor necrosis factor. J. Exp. Med. 163:740-745.
46. Bevilacqua, M. P., J. S. Pober, C. R. Majeau, R. S. Cotran, and M. A Gimbrone. 1984. Interleukin-1 induces biosynthesis and cell surface expression of procoagulant activity in human vascular endothelial cells. J. Exp. Med. 160:618-623.

47. Gajdusek, C., S. Carbon, R. Ross, P. Nawroth, and D. Stern. 1986. Activation of coagulation releases endothelial cell mitogens. J. Cell Biol. 103:419-428.

48. Carney, D. H., W. Redin, and L. McCroskey, 1992. Role of high-affinity thrombin receptors in postclotting cellular effects of thrombin. Semin. Thromb. Hemostasis. 18:91-103.

49. Martel-Pelletier, J., M. P. Faure, R. McCollum, F. Mineau, J. M. Cloutier and J. P. Pelletier. 1991. Plasmin, plasminogen activators and inhibitor in human osteoarthritic cartilage. J. Rheumatol. 18:1863-1871.

50. Treadwell, B. V., M. Pavia, C. A. Towle, V. J. Cooley, and H. J. Mankin. 1992. Cartilage synthesizes the serine protease inhibitor PAI-1: support for the involvement of serine proteases in cartilage remodeling. J. Orthop. Res. 9:309316.

51. Richardson, M., M. W. C. Hatton, and S. Moore. 1988. The plasma proteases, thrombin and plasmin, degrade the proteoglycan of rabbit aorta segments in vitro: an integrated ultrastructural and biochemical study. Clin. Invest. Med. 11:139-450.

52. Lechner, K., P. A. Kyrle, I. Pabinger, and W. Speiser. 1988. Lupus anticoagulant and malignancy related thrombosis. In Hereditary and acquired hypercoagulable states. European School of Haematology, Paris, France. 1-18.

53. Taylor, F. B. 1989. Baboon model of E. coli septic shock: Staging and observations on the role of the vascular endothelium. Crit. Care Med. 10:251283. 